\title{
Optimal Duration of Magazine Promotions
}

\author{
MERCEDES ESTEBAN-BRAVO \\ JOSÉ M MÚGICA \\ JOSE M VIDAL-SANZ \\ Department of Business Economics, Universidad Carlos III de Madrid, C/Madrid, 126. 28903 Getafe, \\ Madrid, Spain
}

\begin{abstract}
The planning of promotions and other marketing events frequently requires manufacturers to make decisions about the optimal duration of these activities Yet manufacturers often lack the support tools for decision making We assume that customer decisions at the aggregated level follow a state-dependent Markov process On the basis of the expected economic return associated with dynamic response to stimuli, we determine the ideal length of marketing events using dynamic programming optimization and apply the model to a complex promotion event Results suggest that this methodology could help managers in the publishing industry to plan the optimal duration of promotion events
\end{abstract}

Keywords: optimal duration of promotion events, Markovian process, dynamic programming

Short-term promotions can suffer from many hidden pitfalls if they are not well planned and controlled (see Strang, 1976). The planning of promotion events should be based on objective procedures such as the maximization of profits or other marketing objectives linked to a particular promotion. The critical decisions of manufacturers are often concerned with the time dimension of promotion events: that is, their frequency (number of events in the planning horizon), timing (dates for each event), and duration (the length of time an event should last). Yet the literature on manufacturers' promotions focuses on timing and frequency rather than duration. This situation exists partly because the duration of promotion events is usually predetermined by the trade, particularly in the case of price discounts (with or without feature and display), the duration of which is fixed by retailers at one week. This focus on frequency and timing is reflected in various approaches to promotion planning, from the perspective of both retailers and manufacturers (Little, 1975; Neslin and Shoemaker, 1983; Cooper et al., 1999). Within this framework researchers have examined the number of times a brand or category should be promoted, the interval between consecutive promotions, and the regularity or homogeneity of inter-promotion times. For price promotions, in fact, the duration of the promotion event has been analyzed only in the context of coupons, the finding being that short-term promotions accelerate purchases, whereas long-term promotions seem not to affect purchase acceleration (Aggarwal and Vaidyanathan, 2003).

In the case of manufacturers' non-price promotions, however, the time dimension is more customized and the duration of a particular promotion is more of a decision factor for 


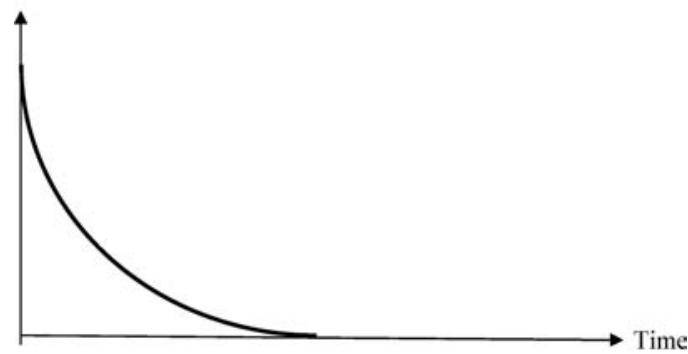

Figure 1 Decay of deal response to the marketing stimuli

the manufacturer. This is the case of value-packaging, in-pack premiums, manufacturing couponing, and other promotion events decided by manufacturers. In particular, manufacturers are less restricted by trade when planning the length of value-pack promotions than when planning the length of price promotions. Unfortunately, despite the large number of academic studies on promotions (e.g., Blattberg and Neslin, 1990; Chandon, 1995), nonprice promotions have received limited attention by marketing researchers. And, when price promotions are either impossible to implement or inadequate, existing research provides little guidance to decision makers (Lichtenstein et al., 1997).

Two conditions are present in a wide variety of marketing activities, particularly in the area of promotions; most of the promotion events show a steady effectiveness decay of economic returns, as represented in Figure 1 (Blattberg and Neslin, 1990, p. 361) and have direct costs associated with the duration of the event.

The study of optimal duration has attracted considerable attention in many scientific disciplines. From the perspective of dynamic optimization, the analysis of the optimal length of time spent in a particular event is called Optimal Stopping Time problem-a type of optimization problem for a random process involving only two possible actions: to stop or to continue. The literature in this area is extensive (see e.g. Bertsekas, 1987; Shiryayev, 1978). These techniques have been applied to several disciplines, including probability and statistics (e.g. Freeman, 1983) and economics and finance (e.g. Myneni, 1992), among others. Although these techniques have enormous potential for application in the marketing context, they have yet to be applied to assist managers in those decisions in which the duration of a marketing activity is involved.

The objective of this paper is to fill this gap by providing a model that, from the perspective of economic returns, should help to plan the optimal duration of promotion events and other marketing actions which could be implemented when two circumstances occur: (a) the marketing stimuli have a steady declining effect, and (b) there are direct costs to maintaining the stimuli. In order to illustrate the potential of the model, we consider serial promotions in the publishing industry, a complex promotional type that will illustrate the model's capability of tackling the duration decision issue in a wide variety of marketing decisions and environments. This empirical setting presents two points of view that make the application 
of the methodology attractive: (1) It is a type of promotion that has not been studied before but which has shown to be effective in diminishing the decline rate of periodical sales, and (2) it is a complex promotion with a unique feature: for a particular customer there is an increase in purchase intention due to the serial reward (the probability of having purchase intention conditional on previous purchases is monotonously increasing as there are stronger incentives to complete the collection; but if the customer defects, the conditional probability is zero as the collection would be incomplete).

The paper is structured as follows. First, we present the general methodology in order to provide a broad view of its potential applicability to marketing decisions where the effect of marketing stimulus shows a steady decay. Second, we consider a complex type of promotion event such as serial promotions, to show the flexibility of this modeling approach. Finally, we discuss the results and provide the conclusions and extensions of the research.

\section{The Methodological Background}

Dynamic programming techniques are the tool most frequently used for dynamic marketingmix planning (see Sethi, 1977; Feichtinger et al., 1994, for a review of dynamic optimal control models in advertising). Closer to the current problem, Mahajan and Muller (1986), Feinberg (1992) and Mesak and Zhang (2001) have looked at optimal scheduling of advertising pulses, among others. In contrast to these papers, we tackle optimal duration of a marketing stimulus on the basis of economic rationale.

Let's consider a marketing dynamic activity, defined by certain set $S=\left\{s_{1}, \ldots, s_{d}\right\}$ of possible states. Let $X$ be a Markov random process, ${ }^{1}$ which summarizes the successive states achieved by the process on the states space $S$. The Markov process is defined over the times $\{0,1,2, \ldots, T\}$ and denoted by $X=\left\{X_{k}\right\}_{k=0}^{T}$, where $T$ can take a finite or an infinite value. Marketing decision makers can apply certain stimuli to modify the probability law of process $X$. When the stimulus is applied, the evolution of process $X$ is ruled by a matrix B of transition probability distributions and managers can decide to stop the stimulus at any time based on the experience up to that time. At period $k$, the control variable can be "applying stimulus" or "not applying stimulus." In case of not applying stimulus at time $k$, the reward in the state $X_{k}$ is $f\left(X_{k}\right)$. Using Bellman's maximum principle, when the stimulus is applied, $V\left(k, X_{k}\right)$ is the optimal reward at time $k$ and the optimal strategy at time $k$ satisfies $V\left(k, X_{k}\right)=\max \left\{f\left(X_{k}\right), E_{B}\left[V\left(k+1, X_{k}\right)\right]\right\}$. As a consequence, an optimal rule is "not applying stimulus" if the reward $f\left(X_{k}\right)$ is greater than the expected optimal reward $E_{B}\left[V\left(k+1, X_{k}\right)\right]$ and "applying stimulus", otherwise. Therefore, the optimal duration of the stimulus is $k^{*}=\min \left\{k: V\left(k, X_{k}\right)=f\left(X_{k}\right)\right\}$.

Sometimes the optimal stopping rule can be implemented at any time; e.g., discount promotions. However, in many marketing activities duration must be planned in advance and $k^{*}$ is an indicative duration choice for future marketing activities; e.g., coupons which are a series of attached tickets often to be collected periodically and needed to obtain a discount or gift on merchandise. Pre-promotion planning involves setting some promotional-test, gathering information about market responses, building a decision model and determining the optimal length of future marketing activities. The stability of the optimal duration can be followed up on the basis of future responses. 
Intuitively, many marketing activities appear to be suitable settings for exploring the potential of these models. In general, the model is an appropriate optimization tool when the following conditions are presented (a) a steady declining effect of the marketing stimuli and (b) direct costs to maintaining the stimuli.

One effective way to capture the steady declining effect of marketing stimuli is to consider that the consumers' response $\left\{X_{k}\right\}$ follows a state-dependent Markovian process. Markovian models have been previously adopted for modeling purchasing behavior (Telser, 1963; Zufryden, 1986) and other marketing problems. ${ }^{2}$ We say that the consumers' response $\left\{X_{k}\right\}$ follows a Markov process if $\operatorname{Pr}\left\{X_{k+1} \mid\left\{X_{j}\right\}_{j=0}^{k}\right\}=\operatorname{Pr}\left\{X_{k+1} \mid X_{k}\right\}$ for each time $k>0$. Let $b=\operatorname{Pr}\left(X_{0}\right)$, with $b_{i} \geq 0$ and $\sum_{i=1}^{d} b_{i}=1$, denote the probability distribution of being in each state $i$ at time 0 and let $B$ define the transition probability matrix containing the probabilities $\operatorname{Pr}\left\{X_{k+1} \mid X_{k}\right\}$. Then, the probability distribution of $X_{k}$ is given by $\operatorname{Pr}\left\{X_{k}\right\}=$ $b^{\prime} B^{k}$. The Markov process is stationary if the probability distribution of $X_{k}$ remains unaltered with the passage of time; i.e. $\operatorname{Pr}\left\{X_{k}\right\}=\operatorname{Pr}\left\{X_{k+1}\right\}$ for any time $k$. This only happens if $b^{\prime}=b^{\prime} B$ or equivalently $\left(I-B^{\prime}\right) b=0$; i.e. $b$ is an eigenvector (normalized to sum one) associated with a unit eigenvalue. ${ }^{3}$

Assume that the consumers' response $\left\{X_{k}\right\}$ to some marketing stimuli and the reward $f\left(X_{k}\right)$ at time $\mathrm{k}$ is a random variable which possible outcomes are $f=\left(f\left(s_{1}\right), \ldots, f\left(s_{d}\right)\right)^{\prime}$. Some of these outcomes may be negative (the application of the stimulus is not profitable), and others positive. As the promotion outcome is ruled by a markovian process, the expected profit is given by

$$
E\left[f\left(X_{k}\right)\right]=E\left[E\left[f\left(X_{k}\right) \mid X_{0}\right]\right]=b^{\prime} B^{k} f,
$$

evolving according to $b^{\prime} B^{k}$. Note that when $b$ is a stationary distribution, the expected profit $E\left[f\left(X_{k}\right)\right]$ is constant for any time $k$. If it is a positive constant, the optimal duration will be infinite, i.e. the stimulus becomes an additional service or characteristic of the product. If it is a negative value, the stimulus should never be applied. But for most of the real world situations, the market responses to marketing stimuli are not stationary. Typically the process starts with $E\left[f\left(X_{0}\right)\right]=b^{\prime} f>0$ and then it exhibits an exponential trend given by $E\left[f\left(X_{k}\right)\right]=b^{\prime} B^{k} f$. In the long term the expected profit $b^{\prime} B^{k} f$ converge to a limit performance value, that we will call $A$ : if $A>0$, the performance of the marketing stimulus is always profitable and its duration should be infinite, but if $A<0$, there is a time $k^{*}$ when the stimulus is not longer profitable and should be stopped. Being the latter the most frequent type of market response, we will use this markovian process in the model presented in the next section.

\subsection{The Model}

The model is built around the idea that in making decisions, manufacturers are trying to maximize consumers' prior purchase intention in order to improve the behavioral response of consumers. We consider a representative potential consumer, whose attitude may be one of two situations, called states, regarding his prior purchase intention. Therefore, there are two types of situations, called states, in which the model explicitly evaluates the expected 
economic value of prior purchase intentions. The prior purchase intention $X$ is an attitudinal variable-i.e., intention to buy-for which there are two possible states. The first type of state is $x^{1}$ when the consumer has a prior purchase intention. The second type is $x^{2}$ when the consumer does not have a prior purchase intention. We consider only two states because a representative magazines' consumer buys none or only one issue.

At the same time, manufacturers should analyze the expected performance of the promotion event. This marketing activity cannot be stopped once it has been launched. However, in the planning process, manufacturers consider the dilemma: "Would it better to have designed the promotion in $k-1$ periods? (which, in dynamic programming terms, is called to stop promoting)" or "Would it better to have designed the promotion in $k$ or more periods? (called to continue promoting)." This analysis will help manufacturers to plan the duration of future promotion events to achieve the best expected return. If promotion continues, the potential customer decides, based on prior purchase intentions, whether to buy the product, denoted by state $z^{1}$; or not to buy the product, denoted by $z^{2}$. Manufacturers aim to enhance the purchase intention $X$ of customers, but they only observe the purchase decision outcome $Z$.

Assuming that the prior purchase intention depends only on the previous intention and not on the consumer's entire purchasing history, we model the decisions process as a Markov chain, the motion of which is governed by the transition probabilities $\operatorname{Pr}\left\{X_{k+m} \mid X_{k}\right\}$, constant for all period $k$. The transition probabilities describe the probability distribution from one decision to another. Let $B$ denote the transition matrix defined as follows:

$$
B=\left(\begin{array}{ll}
\operatorname{Pr}\left\{X_{k}=x^{1} \mid X_{k-1}=x^{1}\right\} & \operatorname{Pr}\left\{X_{k}=x^{2} \mid X_{k-1}=x^{1}\right\} \\
\operatorname{Pr}\left\{X_{k}=x^{1} \mid X_{k-1}=x^{2}\right\} & \operatorname{Pr}\left\{X_{k}=x^{2} \mid X_{k-1}=x^{2}\right\}
\end{array}\right)=\left(\begin{array}{cc}
1 & 0 \\
\theta & (1-\theta)
\end{array}\right) .
$$

The probability that a consumer's state move from $x^{2}$ to $x^{1}$ is constant, $\theta \in(0,1)$, and it does not depend on the number of promoted magazines already being purchased. Since the main utility of the serial promotion-the attainment of a complete collection-cannot be fulfilled once that the first issue is missed, only a particular interest for one spare issue might change the intentions to buy of consumers who had no intentions in the previous issue. These individual values of the spare issues are supposed to be evenly distributed along the different weeks in which the serial promotion is completed. All this means that after a promotion has started, there is a relatively stable proportion of consumers $\theta$ that may change their intentions to buy any spare promoted issue of the magazine. On the other hand, after the promotion has started, the model reflects the rationale of the serial promotion: to make the probability that a consumer's state moves from $x^{1}$ to $x^{2}$ to be zero. This is based on the circumstance that, since the regular issue is on sale simultaneously, any consumer entering the serial promotion (sold at a higher price) is supposed to have a special interest on the collection. Then, if the consumers' main interest is to complete the collection (they would lose all the utility if they abandon the promotion at any time before its completion), the intention to buy remains at its starting value. In a Markovian process context, this is modeled by the assumption that

$$
\operatorname{Pr}\left\{X_{k}=x^{2} \mid X_{k-1}=x^{1}\right\}=0 .
$$


Editorial managers are aware that magazines, after reaching a sales peak at some time, show a downwards trend which is usually tackled with two different strategies: managing a magazine portfolio (introducing and withdrawing magazines according to their life cycle) or/and keeping up sales by an active and intense planning of varied types of promotions (being serial promotions a very effective type). As the aim of our paper is the optimal duration of serial promotions, the behavioral response of consumers without promotions does not provide additional information to the problem at hand.

When a promotion occurs, the probability distribution of purchase decisions depends conditionally on the prior purchase intention at each period $k$, as

$$
\begin{array}{ll}
\operatorname{Pr}\left\{Z_{k}=z^{1} \mid X_{k}=x^{1}\right\}=1, & \operatorname{Pr}\left\{Z_{k}=z^{2} \mid X_{k}=x^{1}\right\}=0, \\
\operatorname{Pr}\left\{Z_{k}=z^{1} \mid X_{k}=x^{2}\right\}=\gamma, & \operatorname{Pr}\left\{Z_{k}=z^{2} \mid X_{k}=x^{2}\right\}=1-\gamma .
\end{array}
$$

Therefore, there is a proportion $\gamma \in(0,1)$ of potential customers who change their minds and decide to buy the promoted product.

An effective way to capture the effects of serial rewards and computing the optimal promotional duration requires the study of $\pi_{k}=\operatorname{Pr}\left\{X_{k}=x^{1} \mid \vec{Z}_{k}\right\}$, the probability distribution of prior buying intention $\left(X_{k}=x^{1}\right)$ conditional on the history of buying behavior $\vec{Z}_{k}=\left(Z_{0}, \ldots, Z_{k}\right)^{\prime}$. Publishers do not usually observe all data $X$, except for the final decision (potential customers either do or do not buy the product). Applying Bayes' rule, we can derive the analytical expression

$$
\pi_{k+1}=\operatorname{Pr}\left\{X_{k+1}=x^{1} \mid \vec{Z}_{k+1}\right\}=\frac{\operatorname{Pr}\left\{X_{k+1}=x^{1} \mid \vec{Z}_{k}\right\} \operatorname{Pr}\left\{Z_{k+1} \mid \vec{Z}_{k}, X_{k+1}=x^{1}\right\}}{\operatorname{Pr}\left\{Z_{k+1} \mid \vec{Z}_{k}\right\}} .
$$

From the probability properties of the buying decision process, we can prove that $\pi_{k+1}=$ $\Phi\left(\pi_{k}, Z_{k+1}\right)$, with

$$
\begin{aligned}
\Phi\left(\pi_{k}, Z_{k+1}\right) & =\frac{\pi_{k}+\left(1-\pi_{k}\right) \theta}{\pi_{k}+\left(1-\pi_{k}\right) \theta+\left(1-\pi_{k}\right)(1-\theta) \gamma} \cdot I\left(Z_{k+1}=z^{1}\right) \\
& =\frac{1-\left(1-\pi_{k}\right)(1-\theta)}{1-\left(1-\pi_{k}\right)(1-\theta)(1-\gamma)} \cdot I\left(Z_{k+1}=z^{1}\right),
\end{aligned}
$$

where $I(Z=a)$ is one when $Z=a$, and zero when $Z \neq a$. This expression can be used to compute iteratively $\pi_{k}$, using the observed data $\vec{Z}_{k}$ and the estimations of parameters $\theta$ and $\gamma$.

Note that $\pi_{k+1}$ is larger than $\pi_{k}$ for $Z_{k+1}=z^{1}$, and vanishes to zero when $Z_{k+1}=z^{2}$. The fact that $\left\{\pi_{k}\right\}$ are monotonously increasing until they vanish (when the representative customer defects) proves that this model essentially captures the nature of serial promotions. In these promotions, the incentive of a particular customer to buy an issue is larger when the previous issue has been acquired and the conditional probability (for those who keep buying until last period) can be expected to increase as time comes, even though sales may decrease due to the nature of the deal response to the marketing stimuli (if the representative customer achieves the deflection state; i.e., $Z_{k}=z^{2}$ ).

Next we focus on the computation of the optimal duration for promotions. Denote by $P^{\prime}>C^{\prime}>0$, the price $(P)$ and cost $(C)$ of the product with promotion; and $P>C>0$, 
the price and cost without promotion. We assume that manufacturers aim to maximize the expected economic value of prior purchase intentions. An optimal stopping rule for promotion is given as follows,

$$
k^{*}=\min \left\{k \in\{1,2,3, \ldots\}: \pi_{k}<\alpha\right\}, \quad \alpha=\frac{C}{P},
$$

where $\alpha \in[0,1]$ since $0<C<P$ (see Appendix for details). In other words, the optimal duration of the promotion event is $k^{*}$ periods, and manufacturers should therefore plan promotions to be no longer than $k^{*}$ periods based on their expected economic value of purchase intentions.

The decision rule reported here is based on a two-state model. Generalization to multistate models is clearly desirable to deal with a number of interesting marketing decision situations. Yet in serial promotions this parsimonious modeling is consistent with our problem as illustrated in the next section.

\section{The Application and Results}

In the publishing industry, where most products are marketed with a fixed resale price, non-price promotions predominate. This is the case for periodical magazines; a common practice in some European countries is to assemble a value pack containing the magazine plus another product to sell at a price above the price of the magazine but below the sum of the expected prices of the two products. One option for publishers is to serialize the promotion by fractioning the additional product in the value pack across different issues of the magazine: a dictionary fractionated in a collection of CDs, for example. We call this type of marketing activity a serial promotion. The marketing objectives of serial promotions are to acquire new customers for the magazine and to increase purchasing frequency among existing customers.

The acquisition of new customers is the basic objective of these promotions, as those who are satisfied with the promoted product have an increased probability of making repeat purchases (see Rothschild and Gaidis, 1981). In fact, new customers may switch from other magazines (secondary demand) during the life of the promotion if they find it to be attractive enough. Alternatively, new customers may not be regular buyers of this type of magazine, but may enter the market (primary demand) when they see an appealing promotion. Hence, it is expected that most of these customers will soon stop participating in the promotion if the value pack does not fulfill their expectations. ${ }^{4}$

Regular buyers may skip some issues, either because they decide not to buy any publication on that occasion or because they switch to another publication. Thus an increase in the purchase loyalty of actual customers is another objective pursued through the use of serial promotions, which reinforce customer loyalty by introducing incentives to decrease skipping behavior and by raising barriers against switching. Customers who purchase a value pack with a low-involvement attitude may stop buying if they do not find the added product to be worthy of the premium price. So, during the serial promotion, a percentage of this type of customer is expected to abandon the purchase of the value pack in the early stages; either they turn to the regular issue or they return to their previous switching behavior. 
What publishers actually pursue is the market response portrayed in Figure 1: a positive immediate response to the deal, followed by effectiveness decay. The previous presentation of the objectives of the promotion gives some hints to understanding the shape of the effect decay of the promotion over time. But the basic explanation to this convex shape is that most entries will take place during the first month; thereafter, the decision of any customer to purchase a value pack at a premium price instead of the regular issue depends on whether or not the customer purchases the previous issue. To enter the promotion after the first month or to re-enter the promotion after skipping one or more issues would mean that the customer, who is paying a premium price, would fail to complete the collection. So, although some customers may demonstrate this behavior, their impact on the total sales of every issue would always be exceeded by the number of defections. Defections occur because customers try the promotion and decide that it is not worth the premium price, or because they skip issues for reasons external to the promotion (e.g. boredom, inconvenience). These defections occur primarily during the first months of the promotion, and the defection rate decreases over time as the commitment of the remaining customers increases. (Discontent with the fifth issue in a collection of six issues would not stop most of the remaining customers from buying the last issue). Expecting such a deal response, the relevant question for publishers is: Following a profit maximization criterion, into how many issues should the added value of the promotion be fractionated?

The optimal stopping time rule previously described is an appropriate tool for determining the ideal length of serial promotions in periodical magazines as there are remarkable statedependence effects on consumers' purchase intentions and final purchase decisions. In order to reinforce the increase in purchase intention due to serial rewards we emphasize the fact that for a representative customer, the probability of purchase an issue conditional on previous purchases increases along the time. Although this is hardly compatible with a decrease in the market deal response, our model allows significant defections as the probability $\operatorname{Pr}\left\{Z_{k+1}=z^{2} \mid \vec{Z}_{k}\right\}>0$, when $\pi_{k}<1$.

We apply the optimal stopping time rule to two specialized magazines, Magazine A and Magazine B, which are published by a multinational publishing company and distributed monthly at different prices, with and without promotion. For Magazine A, which is the leader in the category of Science and Nature magazines, we consider a data sequence that begins November, 1999 and ends September, 2003. For Magazine B, which has the second highest market share in the Business category, data begin April, 2001 and end September, 2003. In particular, we are using their sales data as a measure of consumer responses to promotion in each magazine. Due to the confidentiality policies of the publishing company, sales data were provided as a percentage of the market potential, hereafter called potential market share. Figures 2 and 3 show the monthly values of the potential market share for Magazines A and $\mathrm{B}$, respectively, in which vertical lines denote the end of promotion (promotions are consecutively implemented within the sample period and the exponential decay of their effect is clearly observed in all of them). All figures cover the entire sampling period: 45 months for Magazine A and 30 months for Magazine B. The duration time of serial promotions planned by the publishing industry is 6 or 7 months, what is considered a good rule of thumb based on its experience. 


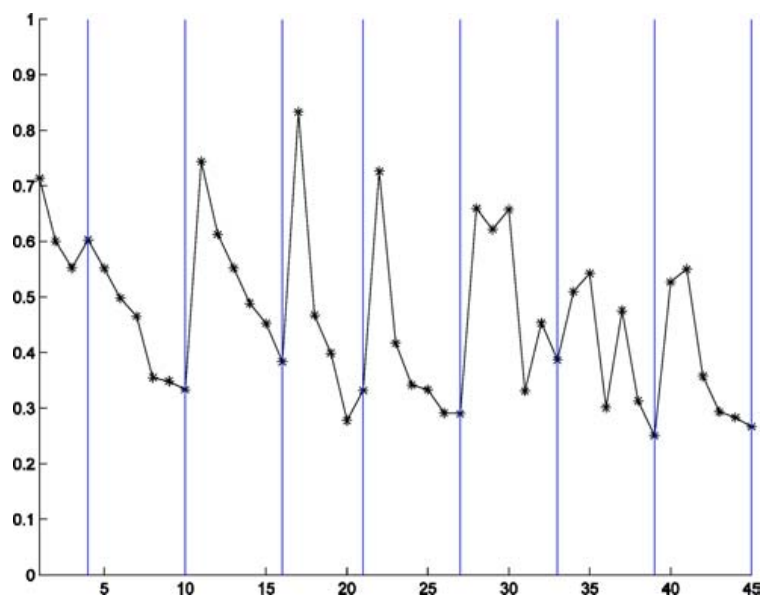

Figure 2 Monthly potential market share of the promoted Magazine A

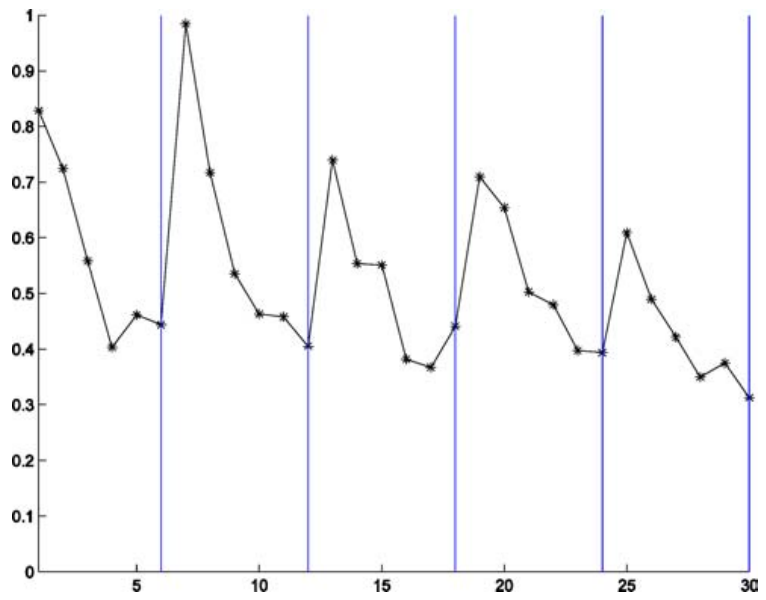

Figure 3 Monthly potential market share of the promoted Magazine B

These magazines were simultaneously sold without promotion at a lower price. Figures 4 and 5 show the monthly values of the potential market share for non-promoted Magazines A and $\mathrm{B}$, which give an indication of the sales baseline. These data allow estimating parameters associated to the purchase intention, $\theta$ and $\gamma$. Also, Figures 4 and 5 show the monthly values of the potential market share for promoted Magazines A and B, which reveals that there is no market cannibalization between promoted and non-promoted magazines as they exhibit slightly procyclical patterns. 


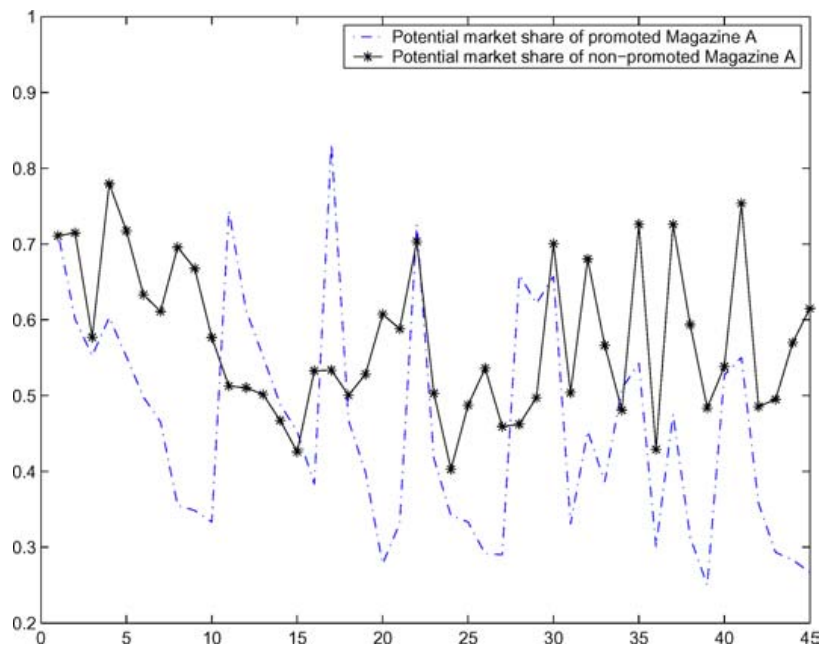

Figure 4 Monthly potential market shares of the promoted and non-promoted Magazine A

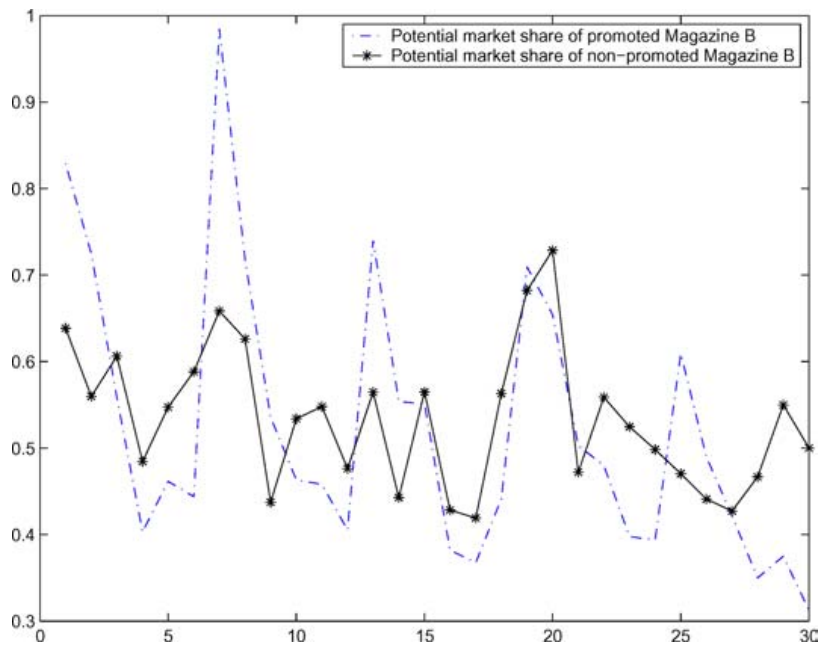

Figure 5 Monthly potential market shares of the promoted and non-promoted Magazine B

Next, following the profit maximization criterion inhered in our model we determine the optimal duration length of serial promotion for Magazines A and B.

Two steps are involved in the task of developing an adequate estimation approach of the parameters $\theta$ and $\gamma$. First, we define the decision variables that describe the consumer 
behavior. Given a threshold at each period $k$, we set the prior purchase intention to buy $X_{k}=x^{1}$, if the potential market share of the non-promoted magazine is larger than the threshold; and $X_{k}=x^{2}$, otherwise. Analogously, we define the variable $Z_{k}$ using the potential market share of the promoted magazine. The second step consists of estimating the parameters $\theta$ and $\gamma$ as follows,

$$
\hat{\theta}=\frac{\sum_{k=2}^{K} I\left(X_{k}=x^{1}\right) I\left(X_{k-1}=x^{2}\right)}{\sum_{k=2}^{K} I\left(X_{k-1}=x^{2}\right)}, \quad \hat{\gamma}=\frac{\sum_{k=2}^{K} I\left(Z_{k}=x^{1}\right) I\left(X_{k}=x^{2}\right)}{\sum_{k=2}^{K} I\left(X_{k}=x^{2}\right)} .
$$

For this problem, we set the threshold at 0.5 , which is the central value of the potential market share in both magazines. For Magazine A, the estimation of parameters $\theta$ and $\gamma$ is $\hat{\theta}^{A}=0.5833$ and $\hat{\gamma}^{A}=0.4167$, respectively; for Magazine $\mathrm{B}$, we obtain $\hat{\theta}^{B}=0.5385$ and $\hat{\gamma}^{B}=0.2308$, respectively.

The aim of launching a promotion is to predispose potential customers to buy a product. However, its effect on sales does not last forever. The length of the promotion should be efficiently chosen according to the sales-promotion process. Accounting for consumer responses to promotion, $\hat{\theta}$ and $\hat{\gamma}$, manufacturers should plan the length of promotion that maximizes their expected return over the planning horizon. Next, we compute the conditional probabilities of purchase intention $\left\{\pi_{k}\right\}$ and the parameter $\alpha$ associated with each magazine in order to determine the optimal promotional duration $k^{*}$ for Magazines A and B.

Figure 6 shows the values of $\left\{\pi_{k}\right\}$ and $\alpha$ for Magazine A, which reveals that the optimal duration for promoting Magazine A is $k^{*}=6$, as $\pi_{k}<\alpha$, for $k=6,7,8 \ldots$ To analyze

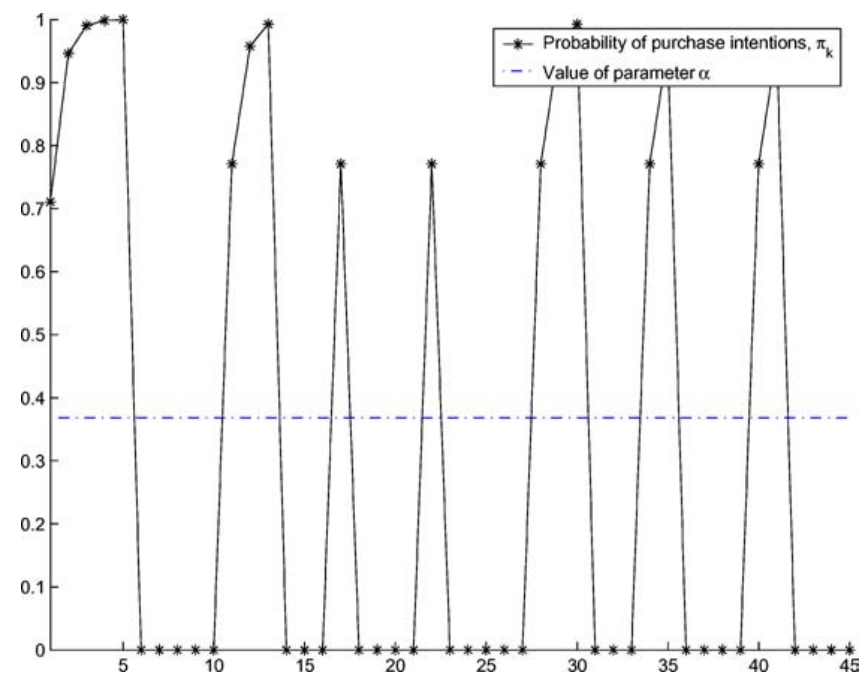

Figure 6 Sequence $\left\{\pi_{k}\right\}$ and line $\alpha$ for Magazine A 


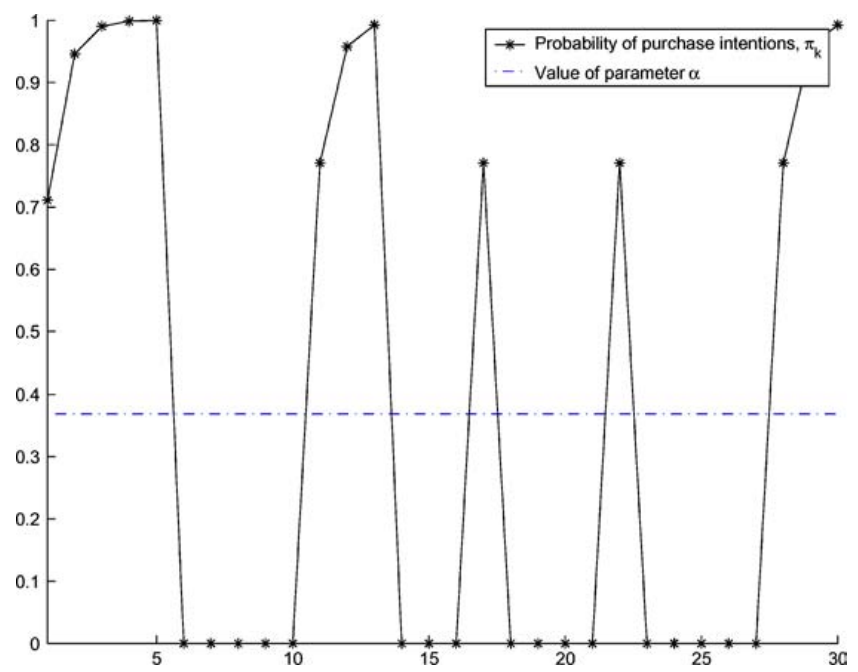

Figure 7 Sequence $\left\{\pi_{k}\right\}$ and line $\alpha$ for Magazine B

this result, we consider the actual average length of promotion, which is 6 (see Figure 3, in which vertical lines denote the end of promotion). These data allow us to conclude that, in the case of Magazine A, the duration of serial promotions planned by the publishing company is the optimal length.

In the case of Magazine B, the optimal duration of serial promotions computed by the model is $k^{*}=4$ (see Figure 7). Currently, the duration time planned by the publisher is 6 months (see Figure 4, denoting the end of promotion with a vertical line), 2 months longer than the length suggested by the model.

The application of our model to the publishers' decisions suggests that the serial promotion of Magazine B should be shortened by two months and that Magazine A's promotion should be maintained at the current six months' duration.

As Figures 2 and 3 show, serial promotion can be sequentially implemented with a fixed length $k$. Next we show that this methodology also is an effective tool for dynamic decision making in the long term. Assume that promotions are sequentially implemented. The return of the first promotion is given by $R_{1, k}=f\left(X_{k}\right)$ and the return rate of the $n$-th promotion is $R_{n, k}=f\left(X_{n k}\right) / f\left(X_{(n-1) k}\right)$, that we assume, stationary and ergodic with $E\left[\left|\ln R_{1, k}\right|\right]<\infty$. Thus, the return after $n$ promotions is $f\left(X_{n k}\right)=R_{n, k} R_{(n-1), k} \ldots R_{1, k}$ and taking logarithms, we have:

$\ln f\left(X_{n k}\right)^{1 / n}=\frac{1}{n} \sum_{i=1}^{n} \ln R_{i, k} \stackrel{\text { a.s. }}{\longrightarrow} M_{k}=E\left[\ln R_{1, k}\right]$, 
by the ergodic theorem. Therefore, the return after $n$ promotions growths exponentially as $f\left(X_{n k}\right) \approx e^{n M_{k}}$ (in the long term planning, a discount factor $e^{-r n}$ should multiply the previous expression). In summary, the long term performance of successive promotions is determined by the return rate of a single promotion $M_{k}$, where the optimal $k^{*}$ would be applied for all successive promotions.

\section{Conclusions and Managerial Implications}

Despite advances in modeling promotion events, much can be done to enlarge the catalogue of techniques for determining the optimal promotion duration. Further development in this direction has practical relevance for marketing managers. Most of the research has overlooked the issue of duration and has focused, rather, on timing (when?) and frequency (how many?), so that models available to assist the short-term planning of promotion events have still not covered the other basic time dimension: duration.

As we have discussed, promotional models available in the marketing literature are of limited use in the context of those promotion events or other marketing initiatives in which customer arrivals, sales, or other phenomena do not occur as a random series of events, but rather in fixed periodical points of time.

We propose a model for fixed timing customer entries. These problems may be found when trying to model the market response of any promotion in which the marketing effect (e.g. sales, arrivals, attendance) is distributed in a time-discrete fashion. Examples can be found in the publishing and entertainment industries (such as periodical publications, TV and broadcasting series, entertainment, and sports events) and in other industries such as transportation (scheduled flights). The analysis also incorporates the state-dependence of purchase decisions by modeling periodical decisions of customers through a Markovian process. Using dynamic programming optimization, we tackle the question of the optimal duration of magazine promotions, taking into account the economic value of purchase intentions.

We show that this methodology is an effective and useful tool for dynamic decision making in the short and long term planning of promotion events. We present a model for serial promotions, and apply this method to two magazines. Our analysis suggests that this approach can determine the optimal duration of serial promotion events in both and that promotion length should be modified in one of them.

One potential limitation of our approach is the requirement of sales data with and without promotion to infer purchase intentions and actual purchase decision. However, when nonpromoted sales are unavailable, this methodology can still be applied by means of a scenariocase analysis for different conjectured parameters $\theta$ and $\gamma$, using the observed purchases as input. Alternatively, the purchase intention without promotion can be estimated by the baseline of promoted sales (see Blattberg and Neslin, 1990, Chapter 9).

We believe that the model and methodology employed in this paper are broadly applicable to other types of promotions and to other industry sectors that require decisions to be made about the optimal duration of marketing activities. In particular, our approach can be applied to a wide range of marketing decision situations that are characterized by 
a steady decay response to marketing stimuli, including situations involving advertising effectiveness, broadcast audiences, and such exhibition attendance as movies.

\section{Acknowledgments}

We thank the participants at the EMAC 2004 conference for their helpful comments and suggestions on earlier drafts of this paper. This research has been partly supported by the European Commission through grants FP6-2004-505509 and FP6-2004-505469, and the Ministerio de Educación y Ciencia of Spain, through projects SEJ2004-00672.

\section{Appendix: Stopping Time Rule}

Assume a planning horizon of $N$ periods. If the promotion has continued to the end of the Nth period, the expected return associated with the sales-promotion process is

$$
V_{N}\left(\pi_{N}\right)=\pi_{N}\left(P^{\prime}-C^{\prime}\right)+\left(1-\pi_{N}\right)\left(-C^{\prime}\right) .
$$

At the end of period $\mathrm{N}-1$, each manufacturer computes its probability distribution of prior purchase intention $\pi_{N-1}$ and decides whether to stop promotion (with the associated expected profit, $\pi_{N-1}(P-C)+\left(1-\pi_{N-1}\right)(-C)$ ) or to continue promotion (with the associated expected profit, $\left.E_{Z_{N}}\left[V_{N}\left(\pi_{N}\right)\right]\right)$. As a consequence, the optimal decision will be one that maximizes the expected return, i.e.,

$$
\begin{aligned}
V_{N-1}\left(\pi_{N-1}\right) & =\max \left\{\pi_{N-1}(P-C)+\left(1-\pi_{N-1}\right)(-C), E_{Z_{N}}\left[V_{N}\left(\pi_{N}\right)\right]\right\} \\
& =\max \left\{\pi_{N-1}(P-C)+\left(1-\pi_{N-1}\right)(-C), E_{Z_{N}}\left[V_{N}\left(\Phi\left(\pi_{N-1}, Z_{N}\right)\right)\right]\right\} .
\end{aligned}
$$

This rule can be extrapolated to all stage $k$, substituting $N$ for $k+1$, so that

$$
V_{K}\left(\pi_{K}\right)=\max \left\{\pi_{k}(P-C)+\left(1-\pi_{k}\right)(-C), E_{Z_{k+1}}\left[V_{k+1}\left(\Phi\left(\pi_{k}, Z_{k+1}\right)\right)\right]\right\},
$$

In order to compute $E_{Z_{k+1}}\left[V_{k+1}\left(\Phi\left(\pi_{k}, Z_{k+1}\right)\right)\right]$, we consider

$$
\begin{aligned}
E_{Z_{k+1}}\left[V_{k+1}\left(\Phi\left(\pi_{k}, Z_{k+1}\right)\right)\right]= & \operatorname{Pr}\left\{Z_{k+1}=z^{1} \mid \pi_{k}\right\} \\
& \times E_{Z_{k+1}}\left[V_{K+1}\left(\frac{1-\left(1-\pi_{k}\right)(1-\theta)}{1-\left(1-\pi_{k}\right)(1-\theta)(1-\gamma)}\right)\right] \\
& +\left(1-\operatorname{Pr}\left\{Z_{k+1}=z^{1} \mid \pi_{k}\right\}\right) E_{Z_{k+1}}\left[V_{K+1}(0)\right],
\end{aligned}
$$

and since $\operatorname{Pr}\left\{Z_{k+1}=z^{1} \mid \pi_{k}\right\}=1-(1-\theta)(1-\gamma)\left(1-\pi_{k}\right)$, then

$$
\begin{aligned}
E_{Z_{k+1}}\left[V_{k+1}\left(\Phi\left(\pi_{k}, Z_{k+1}\right)\right)\right]= & \left(1-(1-\theta)(1-\gamma)\left(1-\pi_{k}\right)\right) \\
& \times V_{K+1}\left(\frac{1-\left(1-\pi_{k}\right)(1-\theta)}{1-(1-\theta)(1-\gamma)\left(1-\pi_{k}\right)}\right) \\
& +(1-\theta)(1-\gamma)\left(1-\pi_{k}\right) V_{K+1}(0),
\end{aligned}
$$

particularly, for the last period, $E_{Z_{N}}\left[V_{N}\left(\Phi\left(\pi_{N-1}, Z_{N}\right)\right)\right]=\left(1-(1-\theta)\left(1-\pi_{N-1}\right)\right) P^{\prime}-$ $C^{\prime}$, so that, $V_{N-1}\left(\pi_{N-1}\right)=\max \left\{\pi_{N-1}(P-C)+\left(1-\pi_{N-1}\right)(-C),\left(1-(1-\theta)\left(1-\pi_{N-1}\right)\right)\right.$ 


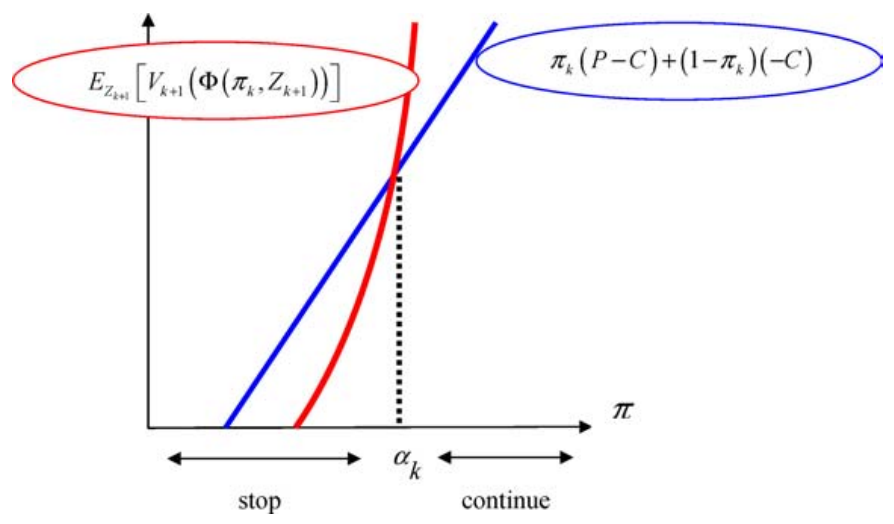

Figure Al The decision threshold at $k$-th period

$\left.P^{\prime}-C^{\prime}\right\}$. For previous periods, this expectation could be iteratively computed backwards.

Consider the decision problem at time $k$, and the value function $V_{K}\left(\pi_{K}\right)$. Whenever the expected profit of terminating promotion is greater than the expected profit under promotion; i.e. if $\pi_{k}(P-C)+\left(1-\pi_{k}\right)(-C)>E_{Z_{k+1}}\left[V_{k+1}\left(\Phi\left(\pi_{k}, Z_{k+1}\right)\right)\right]$, the manufacturer should have designed a promotion of $k$ periods length. Then, solving the equality $\alpha_{k}(P-C)+$ $\left(1-\alpha_{k}\right)(-C)=E_{Z_{k+1}}\left[V_{k+1}\left(\Phi\left(\alpha_{k}, Z_{k+1}\right)\right)\right]$, there is an $\alpha_{k} \in(0,1)$, such that whenever $\pi_{k}<\alpha_{k}$, promotion should have been stopped (see Figure A1).For example at time $N-1$, assuming $P^{\prime}>\left(C^{\prime}-C\right) / \theta$, promotion should be stopped if $\pi_{N-1}<\alpha_{N-1}$, where $\alpha_{N-1}$ solves $\alpha_{N-1}(P-C)+\left(1-\alpha_{N-1}\right)(-C)=\left(1-(1-\theta)\left(1-\alpha_{N-1}\right)\right) P^{\prime}-C^{\prime}$, i.e., $\alpha_{N-1}=\left(C-C^{\prime}\right)+\theta P^{\prime} / P-(1-\theta) P^{\prime}$.The computation of all the thresholds $\left\{\alpha_{k}\right\}$ is involved, so that we consider a simple-to-apply approximation to the solution. Note that $V_{k}(\pi) \leq V_{k+1}(\pi)$ for all $k$ and all $\pi \in(0,1)$ and $V_{k}(\pi)$ is piecewise linear, concave, and increasing in $\pi$. Henceforth, $\alpha_{k-1} \leq \alpha_{k} \leq \alpha_{k+1}$ for all $k$. Publishers should stop production of promoted magazines with negative expected returns, so that $\alpha_{k}(P-C)+\left(1-\alpha_{k}\right)(-C) \geq$ 0 , and therefore $\alpha_{k} \geq C / P$, are valid for all $k$. Because $\alpha=\frac{C}{P} \leq \alpha_{1} \leq \alpha_{2} \leq \cdots \leq \alpha_{k} \leq \ldots$, an optimal stopping rule for promotion is given as follows,

$$
k^{*}=\min \left\{k \in\{1,2,3, \ldots\}: \pi_{k}<\alpha\right\}, \quad \alpha=\frac{C}{P},
$$

where $\alpha \in[0,1]$ since $0<C<P$.

\section{Notes}

1 Markov processes are described in many books on probability (see e g Ross, 1996) Statistical inference for discrete time Markov processes was considered by Billingsley (1961) and Telser (1963)

2 For a review of this topic, see e g Leeflang et al (2000)

3 As $\mathrm{B}$ has non negative elements and its rows sum one, $\mathrm{B}$ has at least a unit eigenvalue 
4. The long-term effectiveness of the promotion event in the acquisition of new customers is rarely large. In one study, publishers of several newspapers estimated that these types of promotions generate an increase of about $1 \%$ of customers (Santana López, 2002).

\section{References}

Aggarwal, P. and R. Vaidyanathan. (2003). "Use It or Lose It: Purchase Acceleration Effects of Time-Limited Promotions," Journal of Consumer Behaviour 2(4), 393-403.

Bertsekas, D. P. (1987). Dynamic Programming, Deterministic and Stochastic Models. Englewood Cliffs: PrenticeHall.

Billingsley, P. (1961). Statistical Inference for Markov Processes. Chicago: University of Chicago Press.

Blattberg, R. C. and S.A. Neslin. (1990). Sales Promotion Concepts, Methods and Strategies. New Jersey: Prentice-Hall.

Chandon, P. (1995). "Consumer Research on Sales Promotion: A State-of-the-Art Literature Review," Journal of Marketing Management 11(5), 419-441.

Cooper, L. G., P. Baron, W. Levy, M. Swisher, and P. Gogos. (1999). "PromoCast: A New Forecasting Method for Promotion Planning," Marketing Science 18(3), 301-316.

Feichtinger, G., R. F. Hartl, and S. P. Sethi. (1994). "Dynamic Optimal Control Models in Advertising: Recent Developments," Management Science 40, 195-226.

Feinberg, Fred M. (1992). "Pulsing Policies for Aggregate Advertising Models," Marketing Science 11, 221-234.

Freeman, P. R. (1983). "The Secretary Problem and its Extensions: A Review," International Statistical Review 51, 189-206.

Leeflang, P. S. H., D. R. Wittink, M. Wedel, and P. A. Naert. (2000). Building Models for Marketing Decisions. International Series in Quantitative Marketing. Boston: Kluwer.

Lichtenstein, D. R., S. Burton, and R. G. Netemeyer. (1997). "An Examination of Deal Proneness Across Sales Promotion Types: A Consumer Segmentation Perspective," Journal of Retailing 73(2), 283-297.

Little, J. D. C. (1975). "BRANDAID: A Marketing-Mix Model. Part I: Structure; Part II: Implementation," Operations Research 23(4), 628-673.

Mahajan, V. J. and E. Muller. (1986). "Advertising Pulsing Policies for Generating Awareness for New Products," Marketing Science 5, 89-106.

Mesak, H. I. and H. Zhang. (2001). "Optimal Advertising Pulsation Policies: A Dynamic Programming Approach," Journal of the Operational Research Society 52, 1244-1255.

Myneni, R. (1992). "The Pricing of American Option,” The Annals of Applied Probability 2(1), 1-23.

Neslin, S. A. and R. W. Shoemaker. (1983). "A Model for Evaluating the Profitability of Coupon Promotions," Marketing Science 2, 361-388.

Rothschild, M. L. and W. C. Gaidis. (1981). "Behavioural Learning Theory: Its Relevance to Marketing and Promotions," Journal of Marketing 45(2), 70-78.

Santana López, Eva. (2002). Las promociones publicitarias en la prensa. Evolución y análisis sistemático de las promociones realizadas entre los años 1990-1998 en la prensa de información general de Cataluña. Universitat Autonoma de Barcelona, Spain.

Sethi, S. P. (1977). "Dynamic Optimal Control Models in Advertising," SIAM Review 19, 685-725.

Shiryayev, A. N. (1978). Optimal Stopping Rules. New York: Springer.

Strang, R. A. (1976). "Sales, Promotion: Fast Growth, Faulty Management," Harvard Business Review 54, 115124.

Telser, L., (1963). "Least Squares Estimates of Transition Probabilities," In: Measurement in economics, Chirst et al. (Ed.), Stanford, California: Standford University Press, pp. 270-292.

Zufryden, F. S. (1986). "Multibrand Transition Probabilities as a Function of Explanatory Variables: Estimation by a Least-Squares-Based Approach,” Journal of Marketing Research 22, 177-183. 